\title{
The effects of a wind farm on birds in a migration point: the Strait of Gibraltar
}

\author{
MANUELA DE LUCAS*, GUYONNE F.E. JANSS and MIGUEL FERRER \\ Department of Applied Biology, Estación Biológica de Doñana (CSIC), Av. M ${ }^{a}$ Luisa s/n, Pabellón de \\ Perú, E-41013 Seville, Spain; *Author for correspondence (e-mail: manuela@ebd.csic.es; fax: +34- \\ 954-621125)
}

Key words: Flight behaviour, Impact on birds of human structures, Spain, Turbine, Wind farm

\begin{abstract}
The interaction between birds and wind turbines is an important factor to consider when a wind farm is constructed. A wind farm and two control areas were studied in Tarifa (Andalusia Province, southern Spain, 30STF590000-30STE610950). Variables were studied along linear transects in each area and observations of flight were also recorded from fixed points in the wind farm. The main purpose of our research was to determine the impact and the degree of flight behavioural change in birds flights resulting from a wind farm. Soaring birds can detect the presence of the turbines because they change their flight direction when they fly near the turbines and their abundance did not seem to be affected. This is also supported by the low amount of dead birds we found in the whole study period in the wind farm area. More studies will be necessary after and before the construction of wind farms to assess changes in passerine populations. Windfarms do not appear to be more detrimental to birds than other man-made structures.
\end{abstract}

\section{Introduction}

During the last century, bird populations have been affected by different kinds of disturbances and impacts due to man-made structures such as highways (Fajardo et al. 1998), power lines (Ferrer et al. 1991; Janss and Ferrer 1998; Penteriani 1998), radio/television towers (Stahlecker 1979; Smith 1985; Nelson and Curry 1995), wind farms (Orloff and Flannery 1992), glass windows (Klem 1990a, 1990b), and due to human activities such as poisoning (Harmata et al. 1999) and illegal shooting (Villafuerte et al. 1998). The increasing mortality of birds by human structures has generated an important literature evaluating the impact of these elements on bird populations and developing the application of protective measures (Klem 1990b; Fajardo et al. 1998; Alonso and Alonso 1999). Nevertheless, the impact of wind farms on birds is one of the less studied impacts and the scientific literature on this topic is scarce.

Wind farms are a relatively new method of obtaining 'clean' energy by avoiding air pollution and other forms of environmental degradation associated with fossil fuel technologies (Nelson and Curry 1995) and have received strong public support as an alternative energy source (Leddy et al. 1999). Moreover, wind farms have shown a spectacular growth because they have reduced the costs of energy 
production. This phenomenon has resulted in a proliferation of wind farms around the world (Germany, Holland, Spain, United States, etc.) (Osborn et al. 2000). In Spain, currently a lot of wind farms are already working or under construction, especially in those areas subject to strong winds such as Cádiz, Castilla-La Mancha, Castilla-León, Cataluña, Galicia, Navarra and The Canary Islands.

Nevertheless, there are three special concerns that arise with respect to the development of wind farms. They represent a source of noise, they have an aesthetic impact on landscapes and they might represent a supplemental negative impact on bird populations (Nelson and Curry 1995).

Wind turbine farms in landscapes have given rise to much controversy relating to bird conservation issues in many European countries (Larsen and Madsen 2000). Wind turbines seem to add an obstacle for bird movements and research has shown that birds fly into the rotor blades (Morrison and Sinclair 1998). Although some studies have recorded bird collisions with rotor blades (Orloff and Flannery 1992; Barrios 1995; Musters et al. 1996; Hunt 1999), other studies gave evidence that birds could detect the presence of wind turbines and generally avoid them (Nelson and Curry 1995; Osborn et al. 1998).

The scarce information on the possible interactions between birds and wind turbines has shown that: (1) waterfowl and raptors seem to be the groups with the highest risk of collision, not directly related to their abundance (Orloff and Flannery 1993; Osborn et al. 1998), (2) familiarity with turbines, leading to a decrease in awareness, may be an important factor contributing to increased mortality (Orloff and Flannery 1993), (3) dark nights increase mortality of waders (Dirksen et al. 1998), (4) passerine species appear to be at greatest risk of colliding during spring and autumn migrations (Higgins et al. 1996; Osborn et al. 1998), and (5) there is evidence that waterfowl, wading bird and raptor densities near turbines are lower (Leddy et al. 1999). Moreover, birds avoid flying in areas with wind turbines and their flight patterns are deferred when wind turbines are rotating or not rotating (Osborn et al. 1998). However, up to now population-level effects have not yet been demonstrated to reject the further development of wind power.

The main purposes of our research were to determine (1) the possible impacts of wind turbines on both the local, breeding and migratory bird populations in one of the most important migration points between Europe and Africa, the Strait of Gibraltar in the south of Spain, and (2) the degree of flight behavioural change in birds resulting from the presence of a wind farm.

\section{Study area}

The study was conducted in Tarifa (Andalusia Province, south of Spain, 30STF590000-30STE610950) from July 1994 to September 1995 (Figure 1). This area was chosen because of the impressive abundance of birds crossing the Strait of Gibraltar, one of the most important migrating routes of the Palearctic (Bernis 1980; Finlayson 1992; Bildstein and Zalles 2000).

In this area, breeding species such as white storks Ciconia ciconia, griffon 


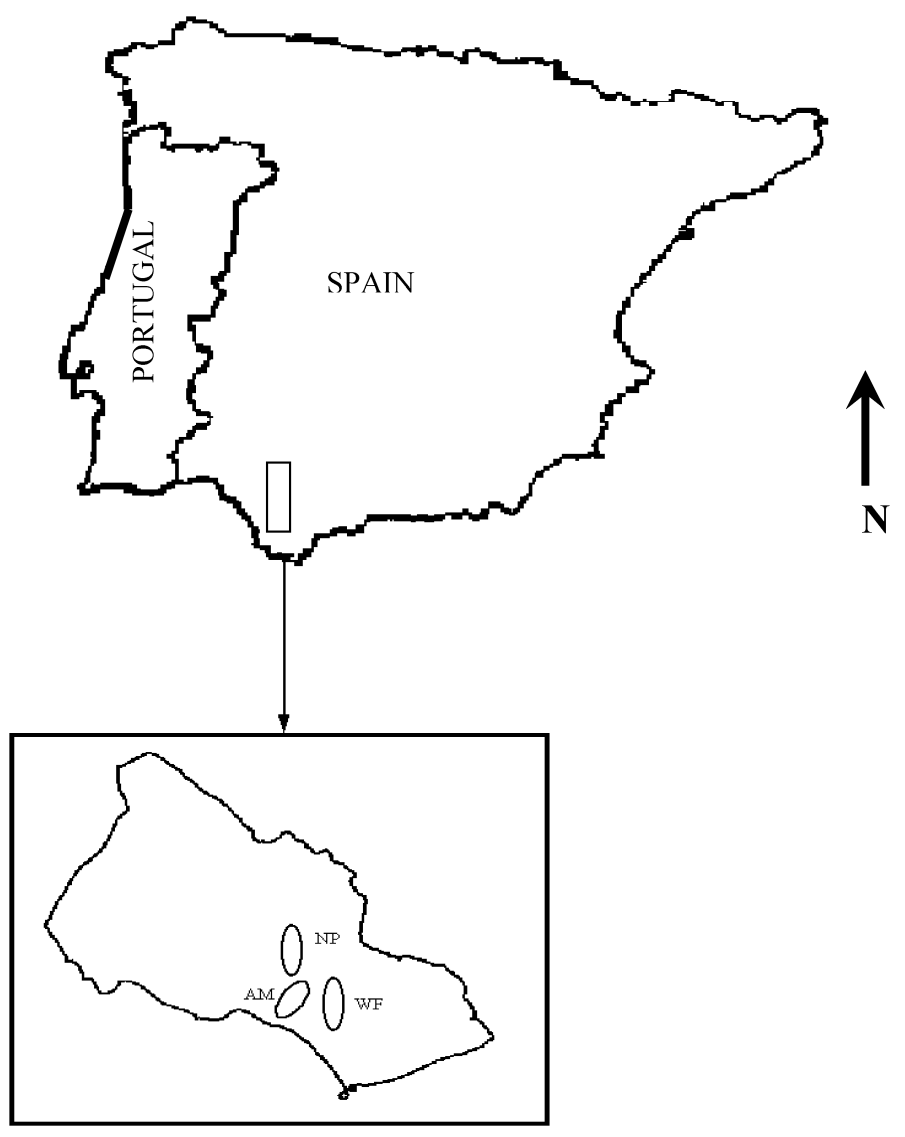

$$
\begin{aligned}
& \mathrm{WF}=\text { wind farm area } \\
& \mathrm{AM}=\text { expansion area of the existing wind farm } \\
& \mathrm{NP}=\text { protected natural area }
\end{aligned}
$$

Figure 1. The three study areas in Tarifa, near the Strait of Gibraltar (Andalusia Province, southern Spain, 30STF590000-30STE610950). WF - wind farm area; AM - expansion area of the existing wind farm; $\mathrm{NP}$ - protected natural area.

vultures Gyps fulvus, common kestrels Falco tinnunculus, Bonelli's eagles Hieraaetus fasciatus, black kites Milvus migrans, peregrine falcons Falco peregrinus, and short-toed eagles Circaetus gallicus can be found. Passerines were abundant in the study area, especially stonechat Saxicola torquata, black-eared wheatear Oenanthe hispanica, dartford warbler Sylvia undata, blue rock thrush Monticola solitarius, thekla lark Galerida theklae, and wren Troglodytes troglodytes. Blanco and González (1992) classified all of these species as not vulnerable in Spain, except for the white stork, Bonelli's eagle and peregrine falcon. 
The study was carried out in the Eólica del Estrecho windplant. This windfarm is situated over a mountain ridge, which ranges in elevation from 550 to $650 \mathrm{~m}$ above sea level. The ridge is orientated north and south. The wind farm consisted of 66 wind turbines AE-20 MADE and 20/150 Ecotècnia. The model AE-20 MADE has a $21 \mathrm{~m}$ tall tubular steel tower and its rotor is $20 \mathrm{~m}$ in diameter. The model 20/150 Ecotècnia has a $24 \mathrm{~m}$ tall tubular tower and its rotor is $20 \mathrm{~m}$ in diameter. Rotors are orientated windward, and have three blades. The total power of the wind farm was 10 MW. The turbine strings were located in two sections, a North Ridge (turbines 1-34) and a South Ridge (turbines 35-66). Both sections were aligned in a single row on the mountain ridge. Within strings, wind turbines were separated by between 60 and $90 \mathrm{~m}$. From now on, we will refer to this area as the WF area (Windfarm).

Two adjacent mountain ridges without turbines were included in this study to be used as a reference for the wind farm. One ridge had an east-west orientation (AM area, which is planned for expansion of the existing wind farm) and the other one had the same orientation as the wind farm ridge (NP area; protected natural area with limited access).

The flora in the three study areas was very similar and characterized by brushwood and few trees (Quercus suber, Q. rotundifolia). The vegetation cover was different among the three study areas: in the WF area zones without vegetation were predominant, whereas in the AM and NP areas zones with dense brushwood and trees predominated.

\section{Study design}

We studied several variables concerning bird population, investigating differences between the wind farm mountain ridge and the two control ridges. Variables were studied along a linear transect with a fixed length in each area. Observations of flight behaviour were also recorded from several fixed observation points in the WF area (see for a similar approach Morrison and Sinclair 1998). Variables recorded were (1) abundance of passerines and soaring birds (birds/m), (2) breeding abundance (no. of nests $/ \mathrm{m}$ ) and productivity of passerines, (3) flight behaviour in the windfarm of soaring birds, and (4) bird mortality due to collision in the wind farm.

\section{Abundance of birds}

The abundance of passerines and soaring birds (griffon vultures, black kites, white storks, common kestrels and short-toed eagles) was registered while walking linear transects in each area (total 228 visits). Transects of fixed length were defined in the three study areas: WF area $2780 \mathrm{~m}$, AM area $1110 \mathrm{~m}$, and NP area $2960 \mathrm{~m}$. Although transects were of fixed length, they were not monitored entirely during each count. A total of $576 \mathrm{~h}$ was dedicated to monitoring the transect areas. For each observation of a bird group, we recorded the bird species, number of birds, climatic conditions (temperature, wind velocity and wind direction), change of flight direction (changes in flight altitude and flight direction for a bird between entering 
and leaving the survey area), activity of the turbines, the period of the year, and the length of the survey section (in $\mathrm{m}$ ).

We defined the breeding period as the period from March to mid-July. The post-breeding migration period was defined as the period from when the birds begin to cross the Strait of Gibraltar (mid-July) until the end of migration (mid-October) (Finlayson 1992). The winter period was defined as the remaining period, which is from mid-October to the beginning of March.

\section{Breeding abundance and productivity of passerines}

The breeding abundance of passerines was registered while walking linear transects in each area. For each passerine group seen, we recorded the species, sex, age and the number of birds. We used the number of passerines divided by meters of transect as breeding abundance measure.

To estimate the reproductive output of breeding passerines in both the windfarm and control areas, we searched for nests during the breeding period. Linear-transect methods were used to detect the nests (Eberhardt 1978). The length of linear transects was defined in the three study areas as in other variables. When we observed a nest of a passerine we recorded the species, the number of eggs and/or chicks (productivity) and the location (vegetation, substrate) where the nest was located. Number of fledged chicks was used as the productivity measure of each nest.

\section{Flight behaviour of soaring birds}

Flight behaviour in the proximity of wind turbines $(150 \mathrm{~m}$ height max. and $100 \mathrm{~m}$ width max.) was recorded by direct observation and by video cameras (total observation: $435 \mathrm{~h}$ ). The flight behaviour of soaring birds was recorded from fixed points. In this case the same variables as those mentioned for abundance of birds were recorded. Three anemometer towers located in the wind farm measured climatic conditions (temperature, wind velocity and wind direction). These variables were recorded at mid-day.

Flight behaviour was expressed by flight altitude and flight direction. Flight altitude and flight direction were calculated by direct observations. Changes in these variables were related to the presence and functioning of turbines. An index of flight direction change was created using the bird's flight direction while entering and leaving the survey area.

We calculated the angular distance between initial flight direction and final flight direction in values from $0^{\circ}$ (no direction change) to $180^{\circ}$ (maximum direction change) (see also Batschelet 1981). An angular distance less than $90^{\circ}$ between initial and final flight direction was considered as a large deviation from the original flight direction. The change in flight height was calculated by subtracting the final flight height from the initial flight height. 
Table 1. Results of mean passerine bird counts (birds $/ \mathrm{km}$ ) along one transect per study area within various periods.

\begin{tabular}{lccc}
\hline & WF area & NP area & AM area \\
\hline Total & $8.5(0.36-81.65)$ & $69.0(0.00-552.78)$ & $23.0(0.45-584.54)$ \\
Breeding & $5.35(0.36-30)$ & $28.25(4.09-182.23)$ & $14.2(0.45-141.67)$ \\
Post-breeding & $15.78(0.36-81.65)$ & $36.44(2.5-126.11)$ & $82.24(2.72-584.54)$ \\
Wintering & $8.76(0.36-42.86)$ & $156.46(0.00-552.78)$ & $9.37(0.91-35.22)$ \\
\hline
\end{tabular}

\section{Bird mortality}

From July 1994 to September 1995 we searched for dead birds resulting from collisions with turbines by checking $50 \mathrm{~m}$ around all turbines on foot (Orloff and Flannery 1992; Morrison and Sinclair 1998). The search frequency was at least once a week by experienced observers (Ferrer et al. 1991; Janss and Ferrer 1998). When a carcass was found, data such as species, age, sex, distance to the closest turbine, kind of injuries and estimated time of death were recorded (Orloff and Flannery 1992; Morrison and Sinclair 1998). Found carcasses were taken away to avoid double counting during subsequent surveys.

\section{Statistical methods}

We used non-parametric statistics for those variables that did not correspond to a normal distribution. We used the Kruskal-Wallis test to compare the abundance of birds between areas. When statistical differences appeared, post hoc comparisons were made with the Mann-Whitney $U$-test. Analysis of $\chi^{2}$ (goodness of fit) was used to determine whether flight direction change was related to the functioning of the wind turbines. Analysis of Spearman Correlation was used to determine whether flight direction change was related to flight height change. We used an $\alpha$-value of $P$ $=0.05$. The SPSS 10.0 statistical package was used to perform all statistical procedures.

\section{Results}

\section{Abundance of birds}

A total of 18831 birds were recorded in the three study area transects during $576 \mathrm{~h}$ of observation. A total of 62227 birds were recorded from fixed observation points in the WF area only during $1917 \mathrm{~h}$ of observation. The flying rates (no. of birds/h of observation) of the most abundant species in the WF area were 20.7 individuals for the white stork, 5.2 for the black kite, 2.8 for the griffon vulture and 1.5 for the swift (Apus apus).

No significant differences between abundance of soaring birds and study areas were detected (Kruskal-Wallis test, $\chi^{2}=0.978, \mathrm{df}=2, P=0.613$ ), recording 
Table 2. Results of bird count (birds $/ \mathrm{km}$ ) along one transect per study area for several soaring species.

\begin{tabular}{lccr}
\hline Species & WF area & NP area & AM area \\
\hline Griffon vulture Gyps fulvus & $8.88(0.36-125.91)$ & $5.23(0.36-11.67)$ & $11.41(0.36-85.91)$ \\
Short-toed eagle Circaetus gallicus & $0.92(0.00-16.11)$ & $0.72(0.34-1.12)$ & $0.70(0.00-3.34)$ \\
Common kestrel Falco tinnunculus & $0.60(0.00-1.67)$ & $0.62(0.56-1.12)$ & $0.58(0.36-2.78)$ \\
White stork Ciconia ciconia & $0.18(0.00-2.50)$ & $0.27(0.01-0.95)$ & $0.19(0.00-0.78)$ \\
Black kite Milvus migrans & $25.94(0.00-1111.12)$ & $34.43(1.12-277.78)$ & $14.4(0.56-73.89)$ \\
\hline
\end{tabular}

30.17 birds $/ \mathrm{km}$ in the WF area, 12.85 birds $/ \mathrm{km}$ in the NP area and 11.55 birds $/ \mathrm{km}$ in the AM area (Table 1).

We detected significant differences between passerine abundance in study areas (Kruskal-Wallis test, $\chi^{2}=15.334, \mathrm{df}=2, P<0.0001$ ). Post hoc analysis indicated significant differences in passerine abundance between WF ( 8.5 birds $/ \mathrm{km})$ and NP (69.0 birds $/ \mathrm{km}$ ) (Mann-Whitney test, $Z=-3.778, P<0.0001)$, and between AM $(23.0$ birds $/ \mathrm{km})$ and NP (Mann-Whitney test, $Z=-2.382, P=$ 0.017). In both cases, passerines were more abundant in the NP area than in the other areas.

These differences in passerine abundance between areas existed during the breeding period (Kruskal-Wallis test, $\chi^{2}=10.057, \mathrm{df}=2, P=0.007$ ), but not during the post-breeding (Kruskal-Wallis test, $\chi^{2}=2.904, \mathrm{df}=2, P=0.234$ ) and winter (Kruskal-Wallis test, $\chi^{2}=3.264$, df $=2, P=0.196$ ) periods.

When we analyzed bird species individually, no statistical differences between study areas were found in the abundance of griffon vultures (Kruskal-Wallis test, $\left.\chi^{2}=0.353, \mathrm{df}=2, P=0.838\right)$, short-toed eagles (Kruskal-Wallis test, $\chi^{2}=$ $1.922, \mathrm{df}=2, P=0.383$ ), black kites (Kruskal-Wallis test, $\chi^{2}=1.782, \mathrm{df}=2, P$ $=0.410$ ) and white storks (Kruskal-Wallis test, $\chi^{2}=2.724$, $\mathrm{df}=2, P=0.256$ ). Only the abundance of common kestrels showed significant differences between the three study areas (Kruskal-Wallis test, $\chi^{2}=10.832, \mathrm{df}=2, P=0.004$ ). Common kestrels were less abundant in the AM area than in the WF (Mann-Whitney test, $Z$ $=-2.933, P=0.003)$ and NP (Mann-Whitney test, $Z=-2.450, P=0.014)$ areas (Table 2).

\section{Breeding abundance and productivity of passerines}

In the WF area more species (45\%) nested in soil without vegetation or between cracks in rocks (Anthus campestris, Galerida thecklae, Monticola solitarius, Oenanthe hispanica), while in the other areas, the species predominantly nested in dense bushes (66\%; Parus caeruleus, Phylloscopus collybita, Certhia brachydactyla, Emberiza cia).

Statistical differences in abundance of passerine nests between study areas were detected (Kruskal-Wallis test, $\chi^{2}=12.225$, $\mathrm{df}=2, P=0.002$ ). In the NP area $(0.0045 \pm 0.0019$ nests $/ \mathrm{m})$, the passerine nests were more abundant than in the WF $(0.0014 \pm 0.0015$ nests $/ \mathrm{m}$; Mann-Whitney test, $Z=-3.328, P=0.001)$ and AM 
Table 3. Abundance of passerine bird nests (nests $/ \mathrm{km}^{2}$ ) per study area for several species.

\begin{tabular}{llll}
\hline Species & WF area & NP area & AM area \\
\hline Tawny pipit Anthus campestris & 0.36 & 0.00 & 0.00 \\
Short-toed treecreeper Certhia brachydactyla & 0.00 & 0.00 & 0.90 \\
Great spotted woodpecker Dendrocopos major & 0.36 & 0.00 & 0.00 \\
Rock bunting Emberiza cia & 0.00 & 0.33 & 1.80 \\
Thekla lark Galerida theklae & 0.72 & 0.00 & 0.00 \\
Blue rock thrush Monticola solitarius & 0.36 & 0.00 & 2.70 \\
Black-eared wheatear Oenanthe hispanica & 2.51 & 0.67 & 1.80 \\
Blue tit Parus caeruleus & 0.36 & 0.00 & 0.90 \\
Chiffchaff Phylloscopus collybita & 0.00 & 0.00 & 0.90 \\
Stonechat Saxicola torquata & 1.80 & 0.00 & 1.80 \\
Dartford warbler Sylvia undata & 0.72 & 0.33 & 7.20 \\
Sardinian warbler Sylvia melanocephala & 0.72 & 0.00 & 0.00 \\
Wren Troglodytes troglodytes & 1.80 & 0.00 & 2.70 \\
Blackbird Turdus merula & 0.36 & 0.00 & 0.00 \\
\hline
\end{tabular}

areas $(0.0023 \pm 0.0019$ nests $/ \mathrm{m} ;$ Mann-Whitney test, $Z=-2.831, P=0.005)$ (Table 3).

When comparing the breeding abundances in the study areas, we observed significant differences (Kruskal-Wallis test, $\chi^{2}=48.688$, df $=2, P<0.0001$ ). Breeding abundance was higher in the AM area $(1.24 \pm 2.44$ birds $/ \mathrm{km})$ than in the WF area $(0.62 \pm 0.44$; Mann-Whitney test, $Z=-6.379, P<0.0001)$ and in the $\mathrm{NP}$ area $(1.00 \pm 1.81$; Mann-Whitney test, $Z=-3.569, P<0.0001)$.

Significant differences in productivity between the study areas were also observed (Kruskal-Wallis test, $\chi^{2}=7.995$, df $\left.=2, P=0.018\right)$ : WF $(0.027 \pm 0.047$ chicks/m; Mann-Whitney test, $Z=-1.862, P=0.063)$ and AM $(0.022 \pm 0.023$ chicks/m; Mann-Whitney test, $Z=-2.873, P=0.004)$ showed higher reproductive output than NP $(0.003 \pm 0.004$ chicks $/ \mathrm{m})$.

\section{Flight behaviour of soaring birds}

We observed 16225 birds from fixed points in the WF area (435 h, 944 registrations). Of those, $71.8 \%$ showed changes in flight direction. When a change in flight direction was detected, $28.5 \%$ showed a large change $\left(<90^{\circ}\right.$ angle).

When we analysed the relationship between flight direction change (177.88 \pm 106.58) and flight height change (46.11 \pm 58.82), no significant relationship was observed (Spearman correlation test, $r_{\mathrm{s}}=0.032, n=176, P=0.669$ ). When comparing the flight direction change between functioning $(182.58 \pm 105.95)$ and non-functioning turbines $(175.27 \pm 109.80)$, we observed a significant difference (Fisher exact test, $P=0.016)$. More flight direction changes were detected $(82.41 \%)$ when turbines were functioning than when turbines were non-functioning $(15.38 \%)$.

Flight height in the WF area during the post-breeding period was significantly higher than during the other study periods (Kruskal-Wallis test, $\chi^{2}=76.113$, df $=$ $2, P<0.0001)$. This difference was also detected in the NP area (Kruskal-Wallis 
Table 4. Mean flight heights $(\mathrm{m})$ of soaring birds in the three study areas and within three study periods.

\begin{tabular}{lccl}
\hline Study period & WF area & NP area & AM area \\
\hline Breeding period & $57.24(-75.00$ to 1000.00$)$ & $45.62(0.00-100.00)$ & $68.20(0.00-500)$ \\
Post-breeding period & $110.02(-200.00$ to 1300.00$)$ & $100.94(-6.00$ to 500.00$)$ & $79.00(-50.00$ to 600.00$)$ \\
Winter period & $58.90(-50.00$ to 500.00$)$ & $37.14(0.00-150.00)$ & $60.07(-10.00$ to 350$)$ \\
\hline
\end{tabular}

test, $\left.\chi^{2}=12.092, \mathrm{df}=2, P=0.002\right)$, but not in the AM area (Kruskal-Wallis test, $\chi^{2}=1.635$, df $=2, P=0.441$ ) (Table 4).

In the post-breeding migration period the flight heights of griffon vulture were higher than in the other study periods, both in the WF $(58.3 \pm 65.3 \mathrm{~m}$; KruskalWallis test, $\left.\chi^{2}=52.866, \mathrm{df}=2, P<0.0001\right)$ and in the NP $(32.3077 \pm 41.1104 \mathrm{~m}$; Mann-Whitney test, $Z=-3.362, P=0.001$ ) areas.

Flight heights of white stork in the post-breeding period differed significantly between study areas (Kruskal-Wallis test, $\chi^{2}=18.883$, df $=2, P<0.0001$ ). Flight height in the WF area $(162.08 \pm 204.65 \mathrm{~m})$ was lower than in the AM (420.00 \pm $238.92 \mathrm{~m}$; Mann-Whitney test, $Z=-3.698, P<0.0001)$ and NP (500.00 \pm 397.64; Mann-Whitney test, $Z=-2.742, P=0.006)$ areas.

Within the WF area, except for white storks $(22.7 \pm 22.6 \mathrm{~m})$, all soaring birds significantly increased their flight heights when crossing lines of the turbines: griffon vultures $(21.4 \pm 57.7 \mathrm{~m}$; Wilcoxon test, $Z=-14.016, P<0.0001)$, short-toed eagles $(3.8 \pm 65.3 \mathrm{~m})$; Wilcoxon test, $Z=-3.981, P<0.0001)$, black kite $(-0.6 \pm 15.6 \mathrm{~m}$; Wilcoxon test, $Z=-3.539, P<0.0001)$ and common kestrels (12.1 $\pm 37.2 \mathrm{~m}$; Wilcoxon test, $Z=-1.74, P=0.08)$.

\section{Bird mortality}

During the whole study period (14 months) only two bird carcasses were found: a young female griffon vulture and an adult male short-toed eagle. They were found under two different towers. This represented a mortality rate of 0.03 birds / turbine/ year.

\section{Discussion}

Our work has clearly demonstrated that birds can detect the presence of turbines and turbines of different size do not represent a significant problem for bird populations. Soaring birds appeared to detect and to avoid the presence of the turbines better when these were functioning, based on changes in their flight direction. Bird abundance was not affected by the presence of turbines. Our observations are supported by the low numbers of dead birds found during the whole study period in the wind farm. Although we did not conduct any experiments of scavenger removal of dead birds, the number of dead birds found in our two visits per week was well below the average found in other studies of power lines using similar methodology (Janss and Ferrer 1998). Bird mortality attributed to turbine collisions was smaller 
than that detected by Hunt (1999) and Osborn et al. (2000). Raptors appeared to be accustomed to the presence of turbines and many of the birds flew close to turbines (Orloff and Flannery 1993). Our results support the conclusion of Nelson and Curry (1995) that mortality of birds associated with the wind farm is not an important factor and avian collisions with turbines are infrequent. In Erickson et al. (2001), turbines constituted $0.01-0.02 \%$ of the avian collisions, which was much lower than other sources of collision mortality such as vehicles, buildings, windows, hightension lines and communication towers. No passerine mortality data were used in this study because it would be necessary to study the predatory actions on small bird carcasses. More studies are necessary about passerine mortality to be able to consider this factor in future wind farms.

No statistical differences in the abundance of soaring birds among the three study areas were detected, except for common kestrels. Our data could represent a further element supporting the idea that soaring birds get accustomed to the presence of turbines (Orloff and Flannery 1993). The difference found for common kestrels might be related to differences in vegetation structure. This species prefers open areas such as in the AM area (Cramp and Simmons 1980).

In contrast, the abundance of passerines in the NP area was higher than in the other areas. Passerine nest abundance was higher in the WF and NP areas than in the AM area, probably due to differences in vegetation structure and habitat differences between the areas, being more dense in the NP area. Leddy et al. (1999) proposed that areas without turbines support higher densities of grassland birds than areas near turbines. Osborn et al. (1998) presented the same results and suggested that passerines, waterfowl and raptors avoid flying near turbines. Also Larsen and Madsen (2000) detected that wind farms caused a habitat loss equivalent to $4 \%$ of the total field area around the turbines for pink-footed geese (Anser brachyrhynchus).

Our data show that passerines had higher productivity near than far from the turbines, while Leddy et al. (1999) detected a linear positive relationship between breeding bird density and transect distance from turbines. An umbrella effect of passerine predators (such as booted eagle Hieraaetus pennatus) in the turbine area on passerine productivity in a wind farm area has been suggested (Fleishman et al. 2001; Suter et al. 2002). However, our work has not explained this result because there were several variables we did not study, such as habitat differences, vegetation structure, vegetation cover, and number of singing males, which may have influenced our results. More studies on passerines are necessary, comparing data before and after the construction of wind farms, to explain these differences.

Our study has shown that $71.2 \%$ of soaring birds changed their flight direction when detecting the turbines at the top of the mountain. Dirksen et al. (1998) detected that only $9 \%$ of the birds crossed the turbine line by passing between the turbines, whereas $18 \%$ turned away from the turbines. Dirksen et al. (1998) also showed that birds changed their flight direction more when the turbines were functioning than when they were stopped. They also concluded that turbine lines might act as flight path barriers. Griffon vultures, short-toed eagles, black kites and common kestrel flight heights differed between entering and leaving the wind farm, perhaps in an effort to avoid turbines. 


\section{Conservation applications}

The results of our study may have important implications for the future development of wind farms. Birds detected the presence of functioning turbines and apparently avoided them by changing their flight direction or increasing their flight height. Because of this, the mortality in this wind farm was practically nil and much less than that reported by Osborn et al. (2000). However, Hunt (1999) reported important mortality for young golden eagles that used the area of the wind farm as a hunting ground. The low risk of the windfarm studied here might be related to the fact that the area is used basically as a flight route and passageway, but not as a feeding, roosting or breeding area, which would induce lower flight heights (the nearest nest of Bonelli's Eagle Hieraaetus fasciatus is $4 \mathrm{~km}$, out of the nearest neighbour distance (NND); Penteriani et al. 2003).

There are some other issues related to wind farms that are necessary to consider. First, wind farms are associated with power lines, a more important cause of avian mortality (Janss 1999), especially because of the extent of the power line network. Erickson et al. (2001) estimated that 750000-1000000 birds were killed annually by collisions with power lines in The Netherlands, and from 130 to 174 million birds per year in the United States. Ferrer et al. (1991) estimated that 400 raptors per year were killed along $100 \mathrm{~km}$ of power lines within and around Doñana National Park, in southwestern Spain (Ferrer et al. 1991). Collision with power lines was considered an important cause of death for some species of birds (Janss and Ferrer 1998). When the wind farm is in a preconstruction phase, effects of associated power lines must be studied to reduce their effect on birds.

Secondly, although birds can detect turbines, long lines of turbines have a potential barrier effect (Dirksen et al. 1998). Shorter turbine rows could reduce this effect, allowing birds to avoid them more easily. If the area is a passageway for migrating birds, the rows of turbines could have this potential barrier effect in the migratory trajectories. Shorter turbine rows may mitigate the barrier effect; this factor needs more research. In all cases, additional research before and after the construction of wind farms is needed to better understand what changes to bird populations installing a wind farm might cause. It is imperative that new wind power developments should be placed in locations of relatively low risk to birds, and that existing wind developments assess negative impacts on birds (Morrison and Sinclair 1998). Specific locations should be evaluated a priori when a wind farm is planned.

\section{Acknowledgements}

We thank all the people who took part in the field work, in particular F. Montoya, M. Castro and I. Sánchez. Dr Vincenzo Penteriani, Dr Carlos Alonso and Roger Jovani helped us with their comments that improved the manuscript. The field study was supported by Ecotècnia S. Coop and by a fellowship grant from a group of seven Spanish wind developers (ENDESA, Cogeneración y Renovables S.A., Aerogeneradores del Sur S.A., Microcentrales de Andalucía S.A., WIGEP Andalucía S.A., 
Wind Ibérica España S.A., PEESA, Alabe la Ahumada S.L.) and from Estación Biológica de Doñana (Consejo Superior de Investigaciones Científicas). M.d.L. would like to extend special thanks to F. Romero, for whose help and support she is indebted.

\section{References}

Alonso J.A. and Alonso J.C. 1999. Mitigation of bird collisions with transmission lines through groundwire marking. In: Ferrer M. and Janss G.F.E. (eds), Birds and Power Lines: Collision, Electrocution and Breeding. Quercus, Madrid, Spain, pp. 121-132.

Barrios L. 1995. Energía eólica y aves en el Campo de Gibraltar. La Garcilla 93: 39-41.

Batschelet E. 1981. Circular Statistics in Biology. Academic Press Inc., New York.

Bernis F. 1980. La migración de las aves en el Estrecho de Gibraltar. Universidad Complutense de Madrid, Madrid, Spain.

Bildstein K. and Zalles J.L. (eds) 2000. Raptor Watch: A Global Directory of Raptor Migration Sites. Birdlife Conservation, London.

Blanco J.C. and González J.L. (eds) 1992. Libro Rojo de los Vertebrados de España. Ministerio Agricultura, Pesca y Alimentación, Madrid, Spain.

Cramp S. and Simmons K.E.L. (eds) 1980. The Birds of the Western Palearctic Vol. II. Oxford University Press, London.

Dirksen S., Winden J.V.D. and Spaans A.L. 1998. Nocturnal collision risks of birds with wind turbines in tidal and semi-offshore areas. In: Ratto C.F. and Solari G. (eds), Wind Energy and Landscape. Balkema, Rotterdam, The Netherlands, pp. 99-107.

Eberhardt L.L. 1978. Transect Methods for Populations Studies. Journal of Wildlife Management 42 : $1-31$.

Erickson W.P., Johnson G.D., Strickland M.D., Young D.P., Sernka K.J. and Good R.E. 2001. Avian Collisions with Wind Turbines: A Summary of Existing Studies and Comparisons to Other Sources of Avian Collision Mortality in the United States. Resource Document, National Wind Coordinating Committee (NWCC), Washington, DC.

Fajardo I., Pividal V., Trigo M. and Jiménez M. 1998. Habitat selection, activity peaks and strategies to avoid road mortality by the little owl Athene noctua. A new methodology on owls research. Alauda 66: 49-60.

Ferrer M., Riva M.D.L. and Castroviejo J. 1991. Electrocution of raptors on power lines in southwestern Spain. Journal of Field Ornithology 62: 181-190.

Finlayson C. 1992. Birds of the Strait of Gibraltar. Academic Press Inc., San Diego, California.

Fleishman E., Blair R.B. and Murphy D.D. 2001. Empirical validation of a method for umbrella species selection. Ecological Applications 11: 1489-1501.

Harmata A.R., Montopoli G.J., Oakleaf B., Harmata P.J. and Restani M. 1999. Movements and survival of Bald Eagles banded in the Greater Yellowstone ecosystem. Journal of Wildlife Management 63: 781-793.

Higgins K.F., Osborn R.G., Dieter C.D. and Usgaard R.E. 1996. Monitoring of Seasonal Bird Activity and Mortality at the Buffalo Ridge Wind Resource Area, Minnesota, 1994-1995. South Dakota Cooperative Fish and Wildlife Research Unit, National Biological Service, Brookings, South Dakota.

Hunt G. 1999. A Population Study of Golden Eagles in the Altamont Pass Wind Resource Area. National Renewable Energy Laboratory (NREL), Santa Cruz, California.

Janss G.F.E. 1999. Avian electrocution on power poles: European experiences. In: Ferrer M. and Janss G.F.E. (eds), Birds and Power Lines: Collision, Electrocution and Breeding. Quercus, Madrid, Spain, pp. 155-174.

Janss G.F.E. and Ferrer M. 1998. Rate of bird collision with power lines: effects of conductor-marking and static wire-marking. Journal of Field Ornithology 69: 8-17.

Klem D. 1990a. Collisions between birds and windows: mortality and prevention. Journal of Field Ornithology 61: 120-128. 
Klem D. 1990b. Bird injuries, cause of death, and recuperation from collision with windows. Journal of Field Ornithology 61: 115-119.

Larsen J.K. and Madsen J. 2000. Effects of wind turbines and other physical elements on field utilization by pink-footed geese (Anser brachyrhynchus): a landscape perspective. Landscape Ecology 15: $755-764$.

Leddy K.L., Higgins K.F. and Naugle D.E. 1999. Effects of wind turbine on upland nesting birds in conservation reserve program grasslands. Wilson Bulletin 111: 100-104.

Morrison M.L. and Sinclair K. 1998. Avian Risk and Fatality Protocol. National Renewable Energy Laboratory (NREL), Golden, Colorado.

Musters C.J.M., Noordervliet M.A.W. and Terkeus W.J. 1996. Bird casualties caused by a wind energy project in an estuary. Bird Study 43: 124-126.

Nelson H.K. and Curry R.C. 1995. Assessing Avian Interactions with Windplant Development and Operation. Translations 60th North American Wildlife and Nature Resource Conferences,. pp. 266-277.

Orloff S. and Flannery A. 1992. Wind Turbine Effects on Avian Activity, Habitat Use, and Mortality in Altamont Pass and Solano County Wind Resource Areas. California Energy Commission (CEC), Sacramento, California.

Orloff S.G. and Flannery A.W. 1993. Wind turbine effects on avian activity, habitat use, and mortality in the Altamont Pass and Solano County Wind Resource Areas. In: Huckabee J.W. (ed.), Avian Interactions with Utility Structures. Avian Power Line Interactions Committee (APLIC). Electric Power Research Institute, Palo Alto, California, pp. 1-14.

Osborn R.G., Dieter C.D., Higgins K.F. and Usgaard R.E. 1998. Bird flight characteristics near wind turbines in Minnesota. The American Midland Naturalist 139: 28-38.

Osborn R.G., Higgins K.F., Usgaard R.E., Dieter C.D. and Neiger R.D. 2000. Bird mortality associated with wind turbines at the Buffalo Ridge Wind Resource Area, Minnesota. The American Midland Naturalist 143: 41-52.

Penteriani V. 1998. Birds and Wind Power Lines. W.W.F., Tuscany Region.

Penteriani V., Balbontín J. and Ferrer M. 2003. Simultaneous effects of age and territory quality on fecundity in Bonelli's eagle Hieraaetus fasciatus. Ibis 145: E77-E82.

Smith J.C. 1985. Perching and roosting patterns of raptors on power transmission towers in Southeast Idaho and Southwest Wyoming. Raptor Research 19: 135-138.

Stahlecker D.L. 1979. Raptor use of nest boxes and platforms on transmission towers. Wildlife Society Bulletin 7: 59-62.

Suter W., Graf R.F. and Hess R. 2002. Capercaillie (Tetrao urogallus) and avian biodiversity: testing the umbrella-species concept. Conservation Biology 16: 778-788.

Villafuerte R.J., Viñuela J. and Blanco J.C. 1998. Extensive predator persecution caused by population crash in a game species: the case of red kites and rabbits in Spain. Biological Conservation 84: $181-188$. 